\title{
AS MÚLTIPLAS FACES DA FOTOGENIA
}

\author{
Les multiples faces de la photogénie \\ The multiple faces of photogeny
}

Darci Raquel Fonseca ${ }^{1}$

\begin{abstract}
Resumo
É na gênese da imagem fotográfica que a ideia de fotogenia, como valor estético destinado à aparência, pode ter sentido. É neste princípio que reside a fotografia. Imponderável, desejada, controvertida, qualidade estética dos seres de luz, fulgurância da imagem, a fotogenia não para de nos surpreender; seu poder de transformação do real em imagem vai além de toda expectativa. Visibilidade fenomenal, ela transforma e nos transforma além da aparência visível. Fotogenia: processo físico-químico ou fruto de uma projeção?
\end{abstract}

Palavras-chave: Fotogenia; aparência; imagem; corpo fotografado

\section{Sommaire}

C'est dans la genèse de l'image photographique que l'idée de photogénie, en tant que valeur esthétique destinée à l'apparence, peut avoir un sens. C'est dans ce principe que la photographie réside. Impossible, désirée, controversée, qualité esthétique des êtres de lumière, fulgurance de l'image, la photogénie n'arrête pas de nous surprendre; son pouvoir de transformation du réel en image dépasse toutes les attentes. Visibilité phénoménale, elle transforme et nous transforme au-delà de l'apparence visible. Photogénie: processus physico-chimique ou fruit d'une projection?

Mots-cle: Photogénie; apparence, image; corps photographié

\begin{abstract}
It is the genesis of the photographic image that the idea of photogenic, while for the aesthetic appearance, may have felt. It is this principle lies the photograph. Imponderable, desired, issue, aesthetic quality of the beings of light, the image radiance photogenic not to surprise us; its power of transformation of the real image beyond all expectation. Visibility phenomenal, she turns and makes us look beyond the visible.
\end{abstract}

Keywords: Photogenic; appearance; image; photographed body 
Provavelmente, é na gênese da imagem fotográfica que a ideia de fotogenia, enquanto valor estético destinado à aparência, pode ter sentido. Vemos aí a necessidade de levar em conta este princípio, pois é nele que reside a matriz da fotografia, ou seja, seu fundamento. William Fox Talbot (1800-1897) foi o primeiro, em 1834-1835, a usar a palavra fotogenia durante suas tentativas de "desenhar com a luz" (BRUNET, 2000, p. 39), através do contato de folhas colocadas sobre uma superfície sensibilizada com cloreto de prata expostas ao sol, gravando os seus "fotogenics drawings" ou desenhos fotogênicos; desde então, o gênio da luz teve seu nome: foto genia. Teria Talbot compreendido naquele momento que o gênio da luz teria ainda muito a nos revelar e a nos surpreender? Teria ele imaginado que a fotogenia causaria tanta controvérsia ao longo da evolução do procedimento fotográfico? Certamente não, pois ele se encontrava imerso na fonte do fenômeno e em confrontação com a ação da luz e o resultado a ser obtido; o vestígio da natureza, uma natureza transformada. A relação com este procedimento ainda era muito direto, "muito técnico para que a ciência se interessasse com isso" (BRUNET, op. cit., p. 39). Nesta fase de suas pesquisas, Talbot não havia ainda se confrontado com o mistério de uma aparência da natureza enobrecida à distância pelo gênio da luz, simplesmente palpada pelo olho aparelhado do fotógrafo. Foi necessário o aparecimento do daguerreótipo, método já mais aperfeiçoado por Daguerre, para que suas experiências fossem publicadas pelo governo francês em 1839, data oficial do aparecimento da fotografia. Contudo, a busca de alguns em obter uma imagem mecanizada conta com Talbot na Inglaterra, Nièpce na França. Desde então, a fotogenia não deixou de ser um problema com o qual nos confrontamos sempre que é o esmaecimento de uma imagem que gostaríamos profundamente objetiva e que, na realidade, é efêmera, antagônica e paradoxal.

Conclui-se que de Niepce a Talbot, Daguerre até os nossos dias, a fotogenia insiste em fazer da fotografia um mundo de visibilidade fenomenal. Atitude estética da realidade representada, a fotogenia é rapidamente integrada como maneira de ser belo sem perder a coesão com a realidade. Objeto de muitas buscas, a fotogenia fez do retrato uma imagem fetiche aberta ao desejo de belas aparências, atingindo nosso universo subjetivo; de toda evidência o universo da imagem e, particularmente, o da nossa imagem no mundo. Ver-se e fazer-se visível segundo a sua melhor aparência, influenciou, certamente, nossa maneira de ser no mundo e a maneira com que levamos o mundo. Com a fotogenia, nos foi dada a ocasião de pensar a força do visível como também as conseqüências deste desejo intenso, de parecer na foto. É possível que a fotogenia se encontre na base do desejo de outras aparências possíveis e cada vez mais diversificadas, pois asseguradas pelo avanço tecnológico e cientifico. Aparências circuladas em escala global e que não deixam de influenciar o olhar sobre si mesmo e sobre o outro. Pensar a fotogenia nos leva ao afrontamento do processo físico-químico-tecnológico que engloba os problemas da imagem e da natureza do indivíduo que se prestou a esta transformação, animada pelo desejo de uma existência visivelmente iluminada e mais duradoura que a fotogenia parece oferecer.

Ainda que controvertida, paradoxal, ilusória e ainda tão desejada e voluntariamente buscada, a fotogenia se apresenta como uma possibilidade de dar à realidade uma existência suplementar e imperceptível do cotidiano vivido. Efêmera, certamente, mas alimento de uma ilusão que nos leva a tentar transparecer nosso ser numa aparente totalidade que a fotografia concentra. Melhor ainda, de aparecer ou ser na aparição segundo outra luminosidade sensivelmente adquirida. Como explicar o que é fotogênico? Seria a maneira de aparecer em uma fotografia? Se a fotogenia é o que aparece pelo efeito da luz, o fotogênico seria então o sujeito (pessoa ou objeto) tal qual ele se mostra visivelmente na imagem. $E$, neste caso, pouco importa se ele aparece belo ou não em outros suportes como a radiografia, pois o que importa é a sua visibilidade. A fotogenia é a força visível das imagens mecânicas e tecnológicas.

A fotogenia instaura uma grande expectativa. Somente após o disparo, determinado e determinante, feito pelo fotógrafo que ela faz sua aparição. A expectativa é mais longa se o processo for analógico. É possível que este "capricho" resulte de uma necessidade própria da fotogenia em reunir certas condições na tomada da foto, na revelação do filme e na cópia, na combinação de pixels, para que possamos ver a realidade em imagem, iluminada por sua luz "engrandecida", como diz Edgar Morin. É assim que a realidade fotogênica da foto se torna singular; seja pelo tratamento da luz e da sombra, ou pelo engajamento das pessoas que ela mobiliza. A fotografia desvenda a parte de luz que a sombra coloca em evidência e que a percepção imediata dificilmente permite ver.

Neste encontro de olhares engajados e marcado pela luz, o fotografado e o fotógrafo se entregam a um ato fotográfico simbólico de apresentação bem mais que a uma mediação tecnológica da luz. É neste ato de criação e de tentativa em fazer transparecer que a significação do retrato como aparição revelada pode fazer a diferença. Neste encontro, movido por imagens, o fotógrafo homenageia pelo seu olhar. Esta maneira de ser diante da câmera fotográfica não é sem sentido, pois é nessa condição que olhamos mais do que vemos; ver é inerente à visão e olhar é convocar os outros sentidos que efetivam o conteúdo simbólico do que aparece em fotografia. Aparecer e parecer outro nesta distinção fotogênica da aparência na imagem é possível se impregnada de expressões afetivas do figurante e do seu intérprete. A imagem, neste caso, não dispensa certamente as coisas vistas, mas seus significados resultam do que é profundamente ressentido.

Essa aventura fotográfica indica que a arte mecânica viria se inscrever na história dos homens, tomados pela incerteza dos esplendores de suas realidades sensíveis e afetivas numa era tecnológica futura. A fotografia deixa em aberto a possibilidade de continuar a transfigurar as coisas visíveis, especialmente, quando o corpo é o objeto de sua própria visibilidade. A fotogenia deve ser explorada segundo aparências e situações muito diferentes. Hélène Samson escreve que, 
O fotogênico enquanto ferramenta teórica da critica, pode designar todos os efeitos estéticos da mediação tecnológica do corpo. Assim o fotogênico, não seria específico da fotografia. Ele se encontra na representação do corpo cada vez que uma mediação tecnológica de sua radiação física acentua o poder psicodinâmico da imagem e abre-lhe um repertório semântico independente de seu referente como exemplifica os 'Genetic Self-portraits' de Gary Schneider. (SAMSON, 2007, p. 711)

Conclui-se, então, que a fotogenia ultrapassa o campo a que fomos habituados a confiná-la, quer dizer, a fotografia. Ela merece ser considerada como objeto de estudo em outros campos de exploração científica, como, por exemplo, o da cirurgia estética que se serve deste valor estético junto aos pacientes. A colaboração da fotogenia com a cirurgia estética é um fato concreto, apesar de serem disciplinas fundamentalmente diferentes, elas se fundam no mesmo desejo que é o da transformação da aparência. Ambas trabalham a aparência que elas transformam em função da luz que os seres projetam.

\section{Fotogenia: imagem da beleza e essência da poesia cinematográfica}

O crítico e historiador de cinema Louis Delluc (1919) pronuncia :"fotogenia, palavra que em um tempo pareceu mágica, ainda hoje, continua sempre misteriosa" (EPSTEIN, 1974, p. 137). Foi o cinema que recuperou a palavra e a popularizou como beleza resultante da produção cinematográfica. Este algo mais que a imagem é capaz de revelar, comumente chamada de fotogenia, fez de Dietrich e Garbo os ícones da beleza que nos interpelam ainda hoje. Com o cinema, vivemos emoções paralelas, emocões que derivam da arte cinéfila e as que nos são próprias. Essas emoções se sobrepõem e confundem nossos sentimentos, como se fossem uma só emoção. Talvez esteja aí a forma ideal de se aproximar do sonho, a realidade cotidiana, muitas vezes, caótica. A fotogenia favorece isso.

O close-up na tela estabeleceu uma relação de proximidade; o duplo que identificamos vive instantes de alegria, de tristeza e de frustrações que absorvemos como se eles viessem de nossas profundezas. Confusos, rimos ou choramos com e por causa desses seres de luz que, sem visibilidade, permanecem enclausurados em seus sarcófagos de gelatina. O movimento iluminado do cinema, obrigatoriamente, alcança o movimento da vida real e a identificação se faz rapidamente; a emoção do personagem não fica na tela e se imbrica com a do espectador. O espectro evanescente de luz se confunde com a nossa vida real de tal forma que, muitas vezes, carregamos por um tempo esta emoção cruzada com a dos seres de luz que o cinema produz. A emoção do sonho contribui com esta interação através de uma rápida familiarização com o fotogênico da imagem. Interação que se instala na esperança do prazer de ver a aparente superioridade da realidade sensível em fusão com a nossa própria vida.

No centro das preocupações de Epstein sobre a poesia do cinema, a fotogenia era a palavra feliz que deveria ser retida, e ele escreve:

Chamarei fotogenia todos os aspectos das coisas, dos seres e almas que elevam a qualidade moral do filme [...] O cinema deve procurar ser gradualmente, unicamente cinematográfico, quer dizer, usar somente elementos fotogênicos. A fotogenia é a mais pura expressão do cinema. (EPSTEIN, 1951, p. 33)

Epstein afirma que "pouca gente compreendeu a importância da fotogenia. Muitos nem mesmo sabem o que é. Ficaria encantado se assumíssemos um acordo misterioso entre a foto e seu gênio" (Ibid., p. 34.). O gênio da foto resulta de sua capacidade em transformar a realidade nos deixando perplexos. Perplexos, pois entre os dois (imagem e realidade), é a luminosidade com a qual o mundo subjetivo e intersubjetivo vem à superfície na imagem. A objetividade aparente da imagem não impede a explosão de emoção provocada por este universo sensível. A emoção estética experimentada diante do duplo fotográfico confirma e reflete a experiência do indivíduo no mundo real. Pouco importa quem olha quem quando as duas realidades entrelaçadas trabalham por elas mesmas, fazendo viver uma parte do sonho. A ficção nos leva a ultrapassar as barreiras impostas pela realidade de cada um de nós. A imagem faz parte de uma categoria de sonhos tanto objetivos quanto nebulosos que convida ao sonho ao mesmo tampo que certifica a proximidade da realidade imediata. Esta é uma característica da relação com o duplo; ou ele está em movimento como no cinema, ou ele é congelado no silêncio eloqüente da foto. Nos dois casos, estamos diante de algo que, inevitavelmente, nos coloca em condição de confronto consigo mesmo e com o outro da imagem.

O conceito de fotogenia ligado ao cinema despertou o interesse de outros pesquisadores que esbarravam sempre com sua improvável definição. Não foi o caso de Jean Epstein, que fez da fotogenia o fio condutor de suas pesquisas relativas à imagem cinematográfica. Para Epstein, o cinema é uma máquina de modelar o tempo; definição esta feita no sentido de uma reflexão mais filosófica e poética do cinema como arte. A fotogenia para ele é uma espécie de magia misteriosa cujo valor é inteiramente estético. Ela é, "essencial e indestrutível; ela é ressentida mas inexplicável; ela é constitutiva mas impossível de ser analisada" (EPSTEIN, 1951, p. 34). Epstein ressalta a importância das sensações que podemos ressentir através de uma experiência estética: não há razão sem emoção. 
A técnica de reprodução atingiu nossas emoções e, ao mesmo tempo, a estética mostrou neste campo que ela também possui suas regras. Mais que a beleza aparente, a fotogenia solicita a essência dos seres e das coisas que a reprodução é capaz de tornar visível e vivaz. Para Epstein, esta vida creditada às aparências se sustenta pelo aspecto mais relevante, a personalidade. Na imagem, a aparência vai além das coisas vistas, e isto confirma a hipótese de que, nela, a beleza não depende de uma beleza anterior à imagem. A imagem revela a beleza segundo seus próprios critérios. "Na tela nós vemos o que o cinema já viu antes de nós: transformação dupla, ou melhor, multiplicada, ela é elevada ao quadrado. Uma escoIha dentro de uma escolha, um reflexo do reflexo. A beleza aqui é polarizada como uma luz" (Ibid., p. 91). Sem esta poesia originada da fotogenia, torna-se impossível experimentar a emoção que o cinema sabe tão bem transmitir. Se Epstein não chega a definir bem a fotogenia em razão de sua imponderabilidade, ele tem o mérito de considerá-la como qualidade estética da imagem mecanizada. A fotogenia, enquanto qualidade estética das aparências obtidas por mediação tecnológica, inaugura um vasto campo de investigação das aparências visíveis.

\section{O gênio da foto é químico ou fruto de uma projeção?}

Figura 01- Foto analógica Raquel Fonseca
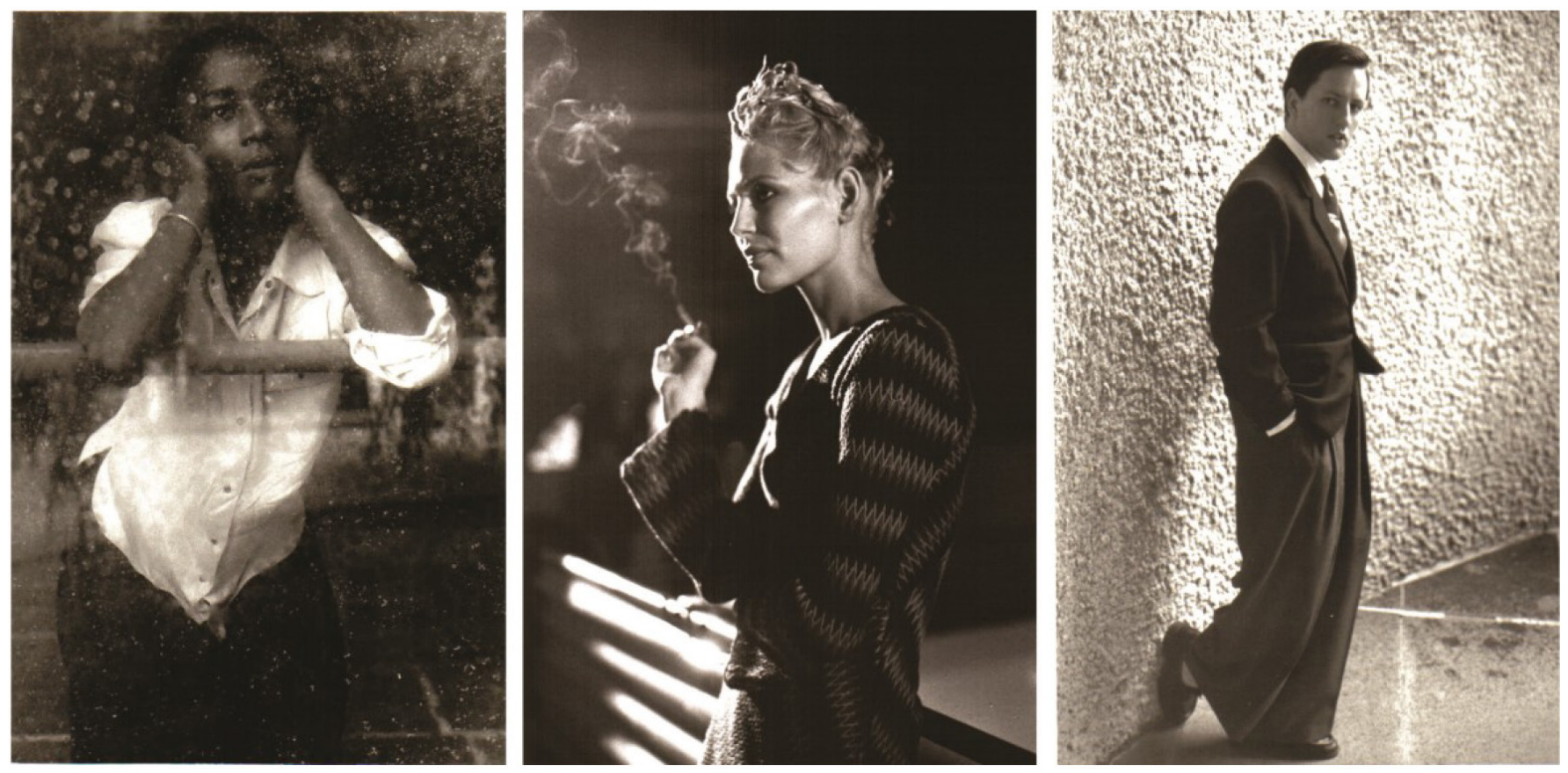

"É a fotografia que em 1839, deu origem à palavra fotogenia" (MORAN, 1956, p. 25), escreve Edgar Morin, salientando que "a fotogenia do cinema não pode se resumir à da fotografia", mas é na imagem fotográfica que reside suas fontes comuns. A foto é estável, mas não é morte, e uma vida aflui no seu espaço interno. A presença daquele que em um dado momento esteve diante da câmera fotográfica é o sustentáculo desta vida interior da foto. Em referência a esta presença, Edgar Morin relembra as palavras de Sartre "como se o original estivesse encarnado na imagem", palavras que, para ele, soam como uma projeção do indivíduo na imagem fotográfica. Morin diz que:

O gênio da fotografia é antes de tudo químico, mas que a riqueza da fotografia é, na realidade, tudo que não está contido nela, mas o que projetamos ou fixamos nela. Tudo se passa como se a qualidade física da imagem fosse mental. Ė a este nível radical do duplo e da imagem mental que se deve apreender a fotogenia. (MORAN, 1956, p. 23)

$\mathrm{Na}$ figura do duplo vemos que os valores afetivos ligam a pessoa ao seu reflexo. Enquanto qualidade de substituto de sua ausência, os valores afetivos garantem a presença do indivíduo ausente. O retrato é, neste sentido, investido de nossos fantasmas.

A questão é relevante, pois essa aparência pode vir a ser o lugar de todas as projeções, sobretudo quando a visibilidade torna-se um fator de integração e de sucesso, como parece ser o caso nas sociedades contemporâneas. Surge, então, a pergunta: a imagem de si é um lugar de projeções profundas de uma existência desejada diferentemente e durável onde o prazer estético serve para enriquecer a comunicação dos seres ou ela vem a ser a razão de projeções vanitosas de um visível ostentatório pelo simples fato de ser visto fazendo desta condição uma forma a existir? Estas duas hipóteses parecem possíveis, visto o número de imagens impostas pelos meios de comunicação que não desprezam os desejos mencionados 
na segunda hipótese, como demonstram as sociedades contemporâneas onde os meios para recriar novos corpos ja não se encontram mais no âmbito da ficção. O desejo fotogênico pode conduzir a extremos.

Retomando a questão da projeção, qualquer que seja a aspiração dada à sua visibilidade na imagem, ela parece inevitável e possui aspirações diversas.

Existe aqui uma incontestável prova estética de si mesmo: ver sua imagem implica olhar para si mesmo, e consequentemente, confrontar-se com suas próprias diferenças. Seríamos capazes de propulsar nossa visibilidade assim como Narciso que, a todo custo, deseja ultrapassar o limite para ver o que existe atrás da aparência, numa fascianação que leva ao abismo da imagem? Simbolicamente, a imagem é sempre um mergulho profundo e a fotografia não foge a esta determinação. Não esquecendo a expériência do espelho que, segundo Jacques Lacan (2000, p. 160), consiste no fato do sujeito que se vê sendo visto por outro como outro.

Através da fotografia, certos indivíduos se livram do evento que metamorfosea o fotografado em "ser" de aparência luminosa, na esperança de concretizar uma ideia elaborada antes mesmo do evento fotográfico.

Se o invidivíduo fotografado oferece tanto dele mesmo, a projeção, neste caso, parece um fato concreto e incontestável condição para fazer da pessoa fotografada um ser fotogênico. E como a fotogenia, neste sentido, é a força esclarecedora que concretiza o desejo de fulgurância de si em uma estética de revelação de alguma coisa ou de alguém que já não está presente, ela é tida como uma força que declara a diferença entre uma realidade objetiva e uma realidade subjetiva e sensivel.

A imagem "pode conter qualidades de vida que o original desconhece" (MORAN, 1956, p. 31), porque ela revela superior ao que se acredita ser na realidade, como também o contrário disso, visto sua capacidade de transformação. A imagem se "lembrará" da presença de quem esteve lá, em um dado momento de sua vida, diante da câmera. Ela torna-se sua historia contada pela visibilidade fotográfica. $\mathrm{O}$ ato fotográfico desvia a cena real para a imagem.

Portanto, não podemos conceber o ato fotográfico sem um au-delà, ou seja, um ultrapassamento técnico e de si mesmo em vista do duplo, das forças visíveis lisonjeiras, a fim de que o evento seja essencialmente da imagem. A fotografia é, em si mesma, um evento; um evento que lida com o tempo e oferece algo que tanto buscamos, que é a esperança de uma durabilidade indeterminada. Fixada no espaço visível, ela é o que é, não permitindo intervenções suplementares à condição de se refazer a foto.

O ato fotográfico comporta uma grande carga de emoção, pois é lugar de encontros envoltos pela força do olhar. Conseqüentemente, é um ato de projeções ao quadrado. Entre um que faz uma doação de si e o outro que capta a imagem, esta não deixa de conter as emoções vividas nesta aventura estética. Uma fotografia não é feita unicamente de informações físicas e óticas, mas, igualmente, da emanação de forças interiores de criação daquele que é visto, tanto quanto daquele que vê. Nele tem-se de lutar com sensibilidade em vista da narureza a fotografar. Diante da sentença "seja natural" quando visados pelo olhar fotografico, a resposta deveria ser sempre: impossivel! É muito dificil permanecer natural pois a natureza se retrai, uma vez visada pela objetiva da câmera. Fica clara a importância da comunicação entre os atores e a necessidade essencial de ultrapassar a fronteira da aparência para que a realidade da imagem seja impregnada de emoções não palpáveis, e que, no entanto, são ressentidas. A magia da fotogenia procede da alquimia dos eflúvios humanos, através de um procedimento capaz de captá-los e torná-los visíveis.

Se colocarmos a fotogenia ao lado da projeção, como sugere Edgar Morin, este ato de parecer que luta com as falsas evidências por uma dessas metamorfoses em verdades profundas pode ser uma emanação do ser através da clareza fotográfica que a espelha como verdadeira. A fotogenia, pela sua maneira oculta de se mostrar, parece algo bem mais elaborado e profundo e se assemelha mais às linguagens elaboradas pelo inconscinente, do que uma pura maquinação. Nesse sentido, o resultado não pode ser outra coisa se não o fruto de uma projeção vinda do inconsciente de um indivíduo desejoso de comunicar sua presença com visibilidade máxima.

Ora, se o inconsciente é a fonte de um pensamento fusionante de coisas futuras, mais rico que o pensamento consciente, parece coerente cogitar que a fotogenia, como projeção do desejo de parecer diferente do que se parece na realidade, possa ser uma projeção que mostra algo diferente do que nós vemos.

\section{As três faces da fotogenia}

A fotografia é a arte da multiplicação; em um único filme o mesmo rosto se revela com aparências múltiplas. Isso mostra que a fotogenia pode exercer sua potencialidade fenomenal em diferentes números de aparências, e se revela através de diversos conteúdos fotogênicos de acordo com as condições de realização e tamanho da imagem. A fotogenia é a qualidade que distingue a foto dos outros modos de representação; no centro propriamente dito desta distinção, Henri Vanlier preconiza as três faces da fotogenia segundo três tipos de aparência visível e três tipos de pose.

1 - A fotogenia imediata, daquelas pessoas que reconhecemos facilmente na foto sem grandes perdas. 0 conteúdo fotogênico nada tem a ver com a beleza, mas com a autenticidade dos seres; eles não se inventam, eles se deixam ser transpostos na imagem.

2 - A fotogenia mediata revela o conteúdo psicológico e biológico imprevisível que se encontra fora do chape- 
Figura 02- Foto analógica Raquel Fonseca
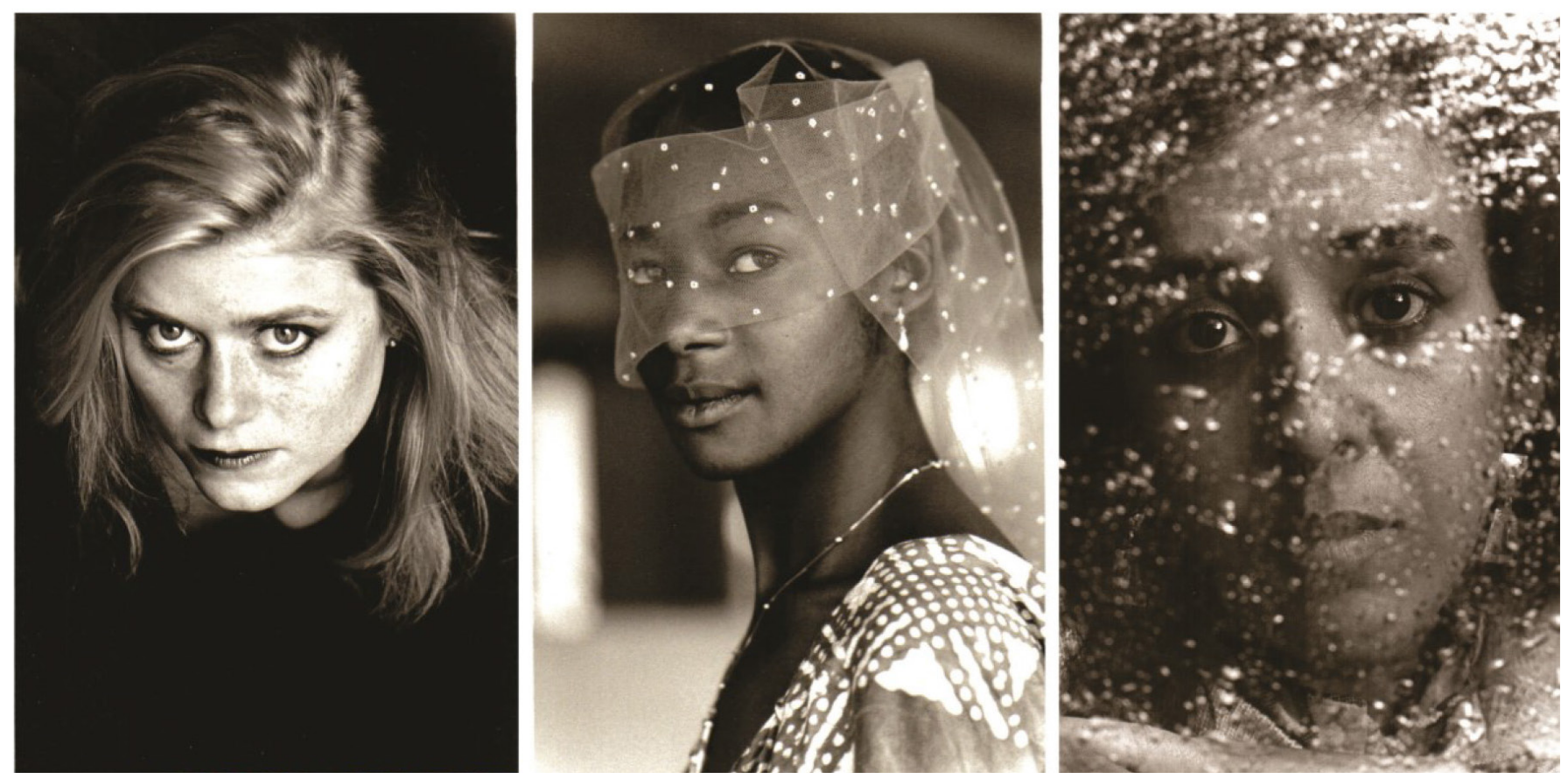

amemnto do negativo. O indivíduo "deixa de se imaginar e permite seu corpo expressar", como nas fotos de Diane Arbus, onde a ação dos indivíduos permanece congelada.

3 - A fotogenia transcendente dos indivíduos cuja aparência aumenta a tensão do processo fotográfico em si mesmo. Uma espécie de disponibilidade absoluta em relação a película, ao papel fotográfico, à tela, ao cinema, como exemplifica Marilyn Monroe e Charles Chaplin.

Essas distinções conferidas à fotogenia distinguem três arquétipos de poses nas tomadas fotográficas: o corte rápido, a parada insistente e a predisposição a ser colocado em imagem. Nestas condições, a fotogenia pode ser obtida, definindo assim a estética da imagem, segundo Henri Vanlier (1983, p. 81).

A pose certamente desempenha um papel fundamental e diferencia consideravelmente os retratos tirados sem o consentimento das pessoas fotografadas. Isso explica que a fotogenia não depende só das propriedades que Ihe são específicas, mas também das pessoas motivadas pelo desejo de ser visto no retrato com uma aparência distanciada da que se tem na realidade. Roland Barthes escreve uma observação muito pertinente; para ele a pose é "o que funda a natureza da fotografia [...] não como alvo, mas como intenção de leitura" (BARTHES, 1980, p. 122). A pose faz parte do ritual de introspecção, de retorno a si mesmo; ela é a base de apoio do olhar fotográfico, parte da relação ritual e do objeto estético da aparição. Os retratos de Nadar exemplificam excelentemente o frescor indefinível do tempo passado que se encontra condensado em suas fotografias. O sujeito da foto é o individuo que nela se vê representado, é o indivíduo que brilha por sua beleza e nos informa sobre ele e, principalmente, sobre a visibilidade da imagem que o representa. Nos retratos de Nadar, o rosto adquire toda sua importância e, tudo que pudesse distrair o espectador foi completamente banido da cena para que o sujeito do retrato fosse verdadeiramente celebrado. A pose, neste caso, é o unico artifício na realização do retrato; ela é o suporte indispensável do duplo idealizado, sua força e sua beleza. O valor dos retratos de Nadar é estético mas também antropológico, pois suas fotos representam a sublevação causada pela possibilidade de se transformar em imagem e confrontá-la com sua própria realidade. A fotogenia parece surgir da captação da imagem não só como fruto exclusivo da tecnologia e do simples olhar aparelhado, mas, também, de um olhar emocionado diante da realidade que faz emergir a imagem e a transforma em foto. É por esta qualidade do olhar que Nadar é uma referência; ele nos ajuda a compreender o que é a fotogenia, quer dizer, "a maneira como o real é engendrado pela luz".

Nome da fotografia na sua gênese, a fotogenia é uma estética capaz de realizar profundas transformações em nossa percepção. Com o cinema, a fotogenia ganhou a face da beleza e, por sua força de comunicação e de identificação, a vida contida na tela passou a ser como a nossa.

O homem se viu transformado através destas imagens fotogênicas, a sociedade se transformou ou se verá ainda mais transformada em função da produção mecânica. A qualidade transformadora da fotogenia ainda não parou de alimentar o desejo de outras aparências, sejam elas através da fotografia, do vídeo ou do cinema. A fotogenia é ainda mais intrigante, quando ela visa diretamente o corpo, talhada na carne através da cirurgia estética onde a aplicação deste conceito não é menos paradoxal. Pensar a fotogenia na contemporaneidade permitiu pensar outras coisas relacionadas a uma estética 
cada vez mais marcada por uma visibilidade, cada vez mais transformada; transformação que nos leva a perguntar em que direção estética estamos indo. Se com a fotogenia o homem ocupou o centro do visível, com a tecnologia digital, através da "hibrigenia", ele se coloca na extrema visibilidade do mundo global que a tecnologia assegura.

\section{Referências}

BARTHES, Roland. La chambre Claire. Paris: Gallimard, 1980.

BRUNET, François. La naissance d'une idée photographique. Paris: PUF, 2000.

EPSTEIN, Jean. Ecrits sur le cinema. Seghers: tome I, 1951.

LACAN, Jacques. Séminaire. Paris: Le Seuil, 2000.

MORIN, Edgar. Le cinéma ou l'homme imaginaire. Paris: Minuit, 1956.

SAMSON, Hélène. Dictionnaire du corps, Paris: PUF, 2007.

VANLIER, Henri. Philosophie de la photographie, Paris: Les cahiers de la Philosophie, 1983. 